

\section{DISCLAIMER}

This report was prepared as an account of work sponsored by an agency of the United States Government. Neither the United States Government nor any agency Thereof, nor any of their employees, makes any warranty, express or implied, or assumes any legal liability or responsibility for the accuracy, completeness, or usefulness of any information, apparatus, product, or process disclosed, or represents that its use would not infringe privately owned rights. Reference herein to any specific commercial product, process, or service by trade name, trademark, manufacturer, or otherwise does not necessarily constitute or imply its endorsement, recommendation, or favoring by the United States Government or any agency thereof. The views and opinions of authors expressed herein do not necessarily state or reflect those of the United States Government or any agency thereof. 


\section{DISCLAIMER}

Portions of this document may be illegible in electronic image products. Images are produced from the best available original document. 
The facilities of Argonne National Laboratory are owned by the United States Government. Under the terms of a contract (W-3 -109-Eng-38) between the U. S. Atomic Energy Commission, Argonne Universities Association and The University of Chicago, the University employs the staff and operates the Laboratory in accordance with policies and programs formalated, approved and reviewed by the Association.

\section{MEMBERS OF ARGONNE UNIVERSITIES ASSOCIATION}

The University of Arizona Carnegie-Mellon University Case Western Reserve University: The University of Chicago Univer sity of Cincinnati Illinois Institute of Technology University of Illinois Indiana University Iowa State University The University of Iowa
Kansas State University The University of Kansas Loyola University Marquette University Michigan State University The Univer sity of Michigan University of Minne sota University of Missouri Northwestern University University of Notre Dame
The Ohio State University Ohio University

The Pennsylvania State University Purdue University Saint Louis University.

Southern Illinois University The University of Texas at Austin Washington Univer sity Wayne State Univerșity The University of Wisconsin

\section{NOTICE}

This report was prepared as an account of work sponsored by the United States Government. Neither the United States nor the United States Atomic Energy Commission, nor any of their employees, nor any of their contractors, subcontrac tors, or their employees, makes any warranty, express or implied, or assumes any legal liability or responsibility for the accuracy, completeness or usefulness of any information, apparatus, product or process disclosed, or represents that its use would not infringe privately-owned rights:

Printed in the United States of America

$$
\text { Available from }
$$

National Technical Information Service

U S Departiment of Commerce

5285 Port Royal Road

Springfield, Virginia 22151

Price: Printed Copy $\$ 3.00$; Microfiche $\$ 0.95$ 
ARGONNE NATIONAL LABORATORY

9700 South Cass Avenue

Argonne, Illinois 60439

DEVELOPMENT AND PERFORMANCE OF A HIGH-SPEED ANNULAR CENTRIFUGAL CONTACTOR

by

G. J. Bernstein, D. E. Grosvenor, J. F. Lenc, and N. M. Levitz

Chemical Engineering Division

January 1973

This report was prepared as an account of work
sponsored by the United States Government. Neither
the United States nor the United States Atomic Energy
Commission, nor any of their employes, nor any of
their contractors, subcontractors, or their employees,
makes any warranty, express or implied, or assumes any
legal liability or responsibility for the accuracy, com-
pleteness or usefulness of any information, apparatus,
product or process disclosed, or represents that its use
would not infringe privately owned rights.

This document is

PUBLICLY RELEASABLE

Bamy steal

Authorizing Official

Date: $\quad 8-24-67$ 


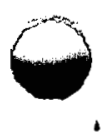

$\bullet$ 
ABSTRACT ........................... 5

I. INTRODUCTION . . . . . . . . . . . . . . 5

II. DESCRIPTION OF THE LONG-ROTOR CENTRIFUGAL CONTACTOR MODIFIED FOR OPERATION IN THE PADDLE MIXING AND ANNULAR MIXING MODES .................. 6

III. TEST FACILITY. . . . . . . . . . . . . . . . . 11

IV. PERFORMANCE TESTS. . . . . . . . . . . . . . . . . . 11

A. Preliminary Tests with a Plastic Contactor . . . . . 11

B. Separating Capacity for Stainless Steel Contactor. . . 12

C. Hydraulic Performance. . . . . . . . . . . 13

D. Effect of Solids on Contactor Operation. . . . . . 16

E. Determination of Extraction Efficiency . . . . . . 17

V. DISCUSSION AND CONCLUSIONS . . . . . . . . . . . . . 22

ACKNOWLEDGMENTS. . . . . . . . . . . . . . . . . . . 24

REFERENCES . . . . . . . . . . . . . . . . . . . 24 
1. Experimental Long-Rotor Centrifugal Contactor (PaddleMixing Type). . . . . . . . . . . . . . . . 7

2. Rotor and Mounting Plate. . . . . . . . . . . . . 8

3. Isometric View of Air-Controlled Weir . . . . . . . . . . 9

4. Schematic Drawing of Annular Centrifugal Contactor. . . . . . 10

5. Experimental Annular-Mixer Centrifugal Contactor with Large Bottom Section. . . . . . . . . . . . . . . 14

6. Baffle Plate--Straight Baffles. . . . . . . . . . . 14

7. Baffle Plate--Curved Baffles. . . . . . . . . . . . 14

8. Separating Capacity of Centrifugal Contactor with 4-in.-dia Rotor--Annular Mixing Mode. . . . . . . . . . . . .

1. Summary of Contactor Runs with $\mathrm{MnO}_{2}$ Solids (Annular Mixing Mode)... . . . . . . . . . . . . . . . .

2. Stage Efficiencies in Uranium Extraction (Annular Mixing Mode) . . . . . . . . . . . . . . . . . . . .

3. Stage Efficiencies In Uranium Stripping (bypass 1ine closed, Annular Mixing Mode).

4. Stage Efficiencies in Uranium Stripping (bypass line open, Annular Mixing Mode). . . . . . . . . . . . . . . 


\title{
DEVELOPMENT AND PERFORMANCE OF A HIGH-SPEED ANNULAR CENTRIFUGAL CONTACTOR
}

by

G. J. Bernstein, D. E. Grosvenor, J. F. Lenc, and N. M. Levitz

\begin{abstract}
A centrifugal contactor of novel design has been developed for the solvent extraction processing of nuclear fuels. The novel aspect is that the aqueous and organic solutions are fed directly into the annulus between the hollow 4-in.-dia rotor and the casing and are mixed by skin friction as they flow downward. This design eliminates the mixing chamber, mixing paddle, and injection nozzle employed in the centrifugal contactor design developed at the AEC's Savannah River (SR) Plant. High throughput is achieved by the high length-to-diameter (L/D) ratio combined with high operating speed (to $3500 \mathrm{rpm}$ ).

Separating capacities with synthetic Purex-type solutions [i.e., 0.5M nitric acid and 30\% tributyl phosphate (TBP) in n-dodecane diluent] ranged from about $5 \mathrm{gpm}$ at $2000 \mathrm{rpm}$ to about $15 \mathrm{gpm}$ at $3500 \mathrm{rpm}$. Essentially $100 \%$ stage efficiency was demonstrated in extraction and stripping tests with uranium as the solute. Mechanical performance was very good throughout the tests.
\end{abstract}

\section{INTRODUCTION}

A program was undertaken to adapt the Savannah River (SR) paddlemixer type centrifugal contactor to a critically favorable configuration suitable for efficient processing of high-plutonium systems. Such systems are basic to the solvent extraction processing of fast breeder reactor fuels. The approach was to investigate the performance characteristics of small-diameter, long-rotor, high-speed units, in which it is necessary to achieve criticality safety and yet maintain high capacity.

Earlier in this investigation, a stainless steel centrifugal contactor was designed, built, and tested that comprises principally a hollow rotor suspended from a top spindle assembly and rotating within a fixed casing. No bottom bearing was provided to avoid problems that might be encountered if there were a bottom bearing operating in the corrosive process solutions. Beneath the rotor, which has a 4-in. ID by 12-in. settling section, is a mixing chamber. The rotor diameter is small enough to provide criticality safety in the processing of high-plutonium fuels (e.g., LMFBR fuels). 
During the design phase of this investigation, an alternative design of centrifugal contactor was conceived--the annular-mixer centrifugal contactor--which appeared to have the advantages of simplicity of construction and operation. A plastic model of an annular centrifugal contactor was fabricated and operated, demonstrating the general feasibility of the concept. A stainless steel centrifugal contactor ${ }^{1}$ subsequently constructed for operation in the Savannah River mixing mode was designed so that it could readily be converted for operation in the annular mixing mode. Details of the design and development of this unit when operated in the SR mixing mode are presented in a companion report ${ }^{1}$ that complements this report.

In both designs, the mixture enters an orifice in the bottom of the hollow rotor, and as the phases flow up through the rotor, they are separated by centrifugal force. The separated phases flow over weirs (in the rotor) and are discharged into collecting rings and the exit piping.

This report presents a brief description of the ANL adaptation of the SR-type centrifugal contactor and summarizes the mechanical performance, separating capacity, and extraction efficiency tests of the novel annularmixer unit. The annular design is not ljmited to small-diameter contactors, and its simplified construction features should make it particularly attractive for systems requiring remote maintenance.

\section{DESCRIPTION OF THE LONG-ROTOR CENTRIFUGAL CONTACTOR MODIFIED FOR OPERATION IN THE PADDLE-MIXING AND ANNULAR MIXING MODES}

The design and operation of two modifications of the ANL stainless steel centrifugal contactor with a 4-in.-ID rotor are described here. The first modification is for operation in the SR mixing mode and the other for operation in the annular mixing mode. The basic features of the ANL long-rotor contactor when modified for operation in the SR mixing mode are shown in Fig. 1. Aqueous and organic phases enter the mixing chamber and are vigorously mixed by a paddle attached to the shaft that supports the rotor.

Mixing in the mixing chamber effects transfer of solute from one phase to the other. The mixture is ejected from the mixing chamber through openings in its periphery into the zone above the chamber. Four fixed radial baffles direct the mixture through the nozzle into the $13 / 16-i n .-$ dia orifice at the bottom of the rotor. The deflection baffle above the orifice prevents the mixture from bypassing part of the settling zone and directs it to the outer regions of the rotor, where the centrifugal force is higher. Vent holes in the baffle permit entrained air to escape from the mixture to the space inside the rotor adjacent to the rotor shaft.

Figure 2 shows the rotor in position below the support plate. The deflection baffle is partially visible through the rotor orifice. The small hole in the baffle is one of several for venting air entrained with the mixed phases. The function of the Teflon seals at the top of the rotor are to protect the spindle bearing against corrosive reagent fumes. 


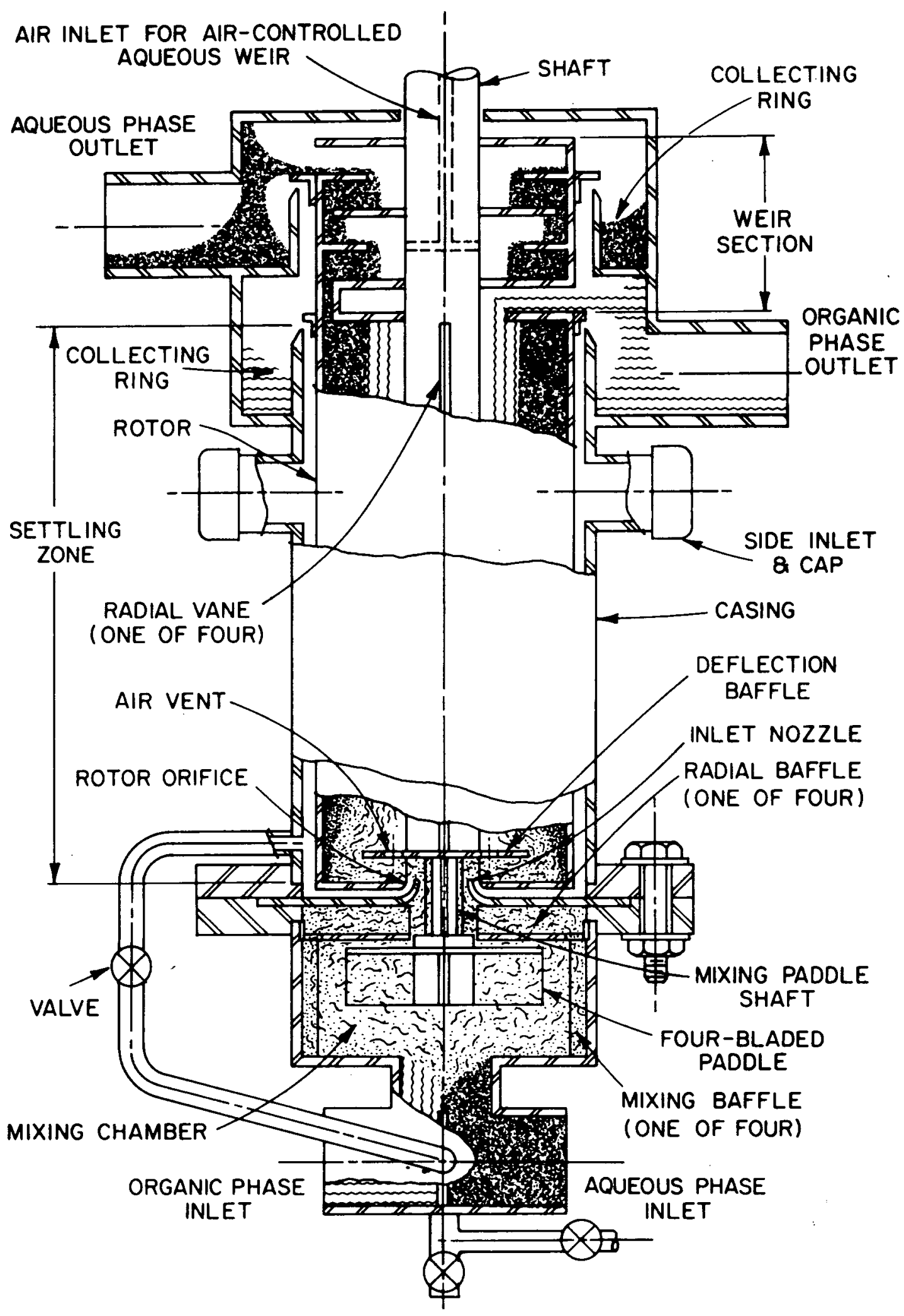

FIG. 1. Experimental Long-Rotor Centrifugal Contactor (Savannah River Type) 


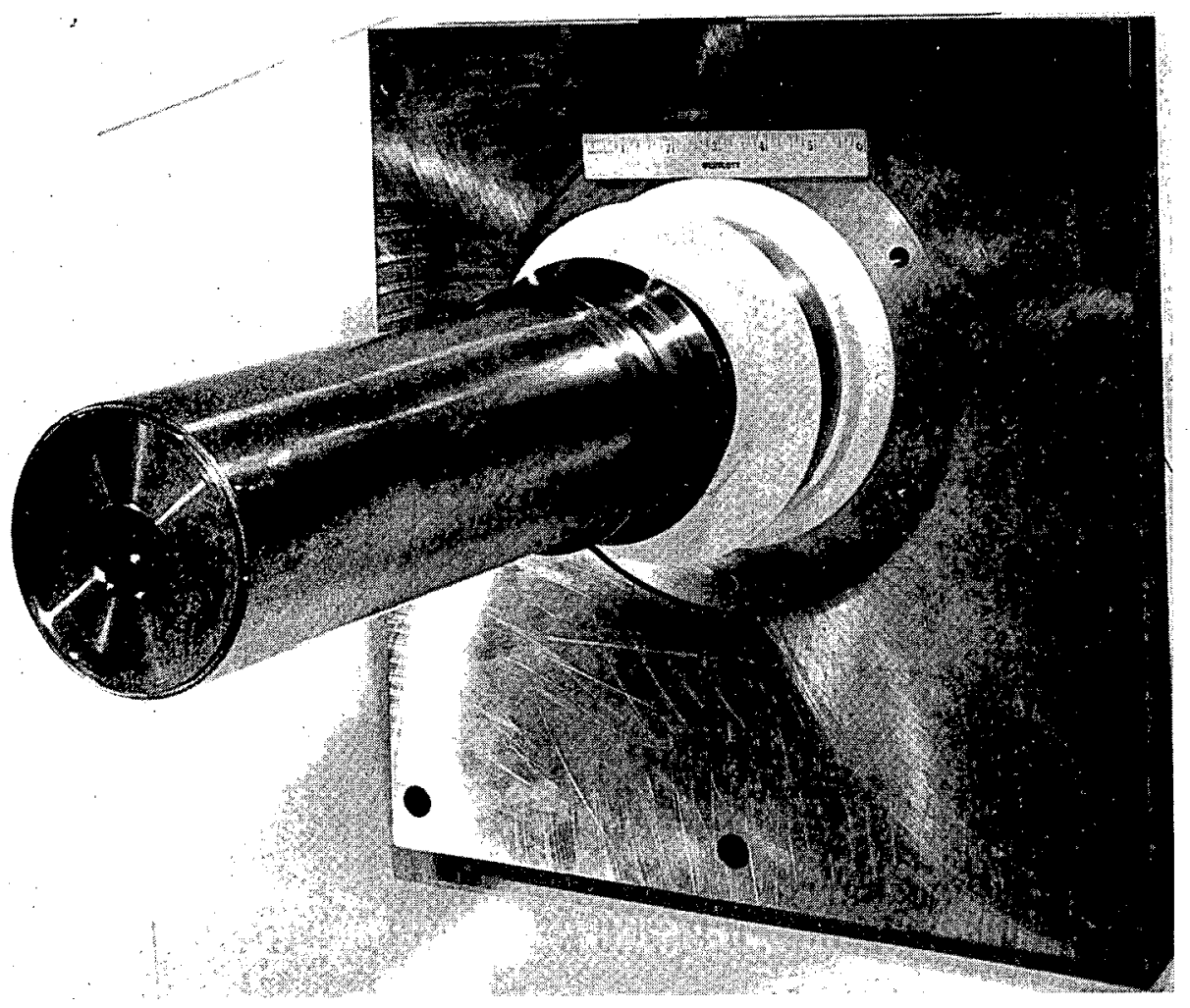

FIG. 2. Rotor and Mounting Plate

(ANL Neg. No. 308-2365)

The volume above the seals is purged with air to remove any fumes that penetrate the seals. This seal design was used in the experimental model since it was desired to keep the rotor as close as possible to the spindle in order to increase its critical speed. In a production model, a lighter rotor and a longer shaft would be used and the mounting assembly would be designed to permit removal of the entire rotor and spindle assembly by a direct upward motion.

Four vertical vanes on the rotor shaft accelerate the mixture to rotor speed. As the fluid flows through the rotor, the heavy (aqueous) phase moves outward, displacing the light (organic) phase inward. Separation of the mixed phases under centrifugal force (about $450 \mathrm{~g}$ at $3500 \mathrm{rpm}$ ) achieves a much more rapid separation than could be achieved under the force of 1 gravity.

The aqueous phase then flows through a system of weirs (see Fig. 3) to the upper discharge ports, while the organic phase flows over an inner weir and is discharged through four passages built in the form of a hollow cross. Any air entrained in the mixture is discharged with the organic phase. The effluent streams are discharged into collecting rings and leave through tangential outlet lines. If a number of contactors should be arranged in series for countercurrent solvent extraction, the effluent streams would become inlet streams to the adjacent contactors. 


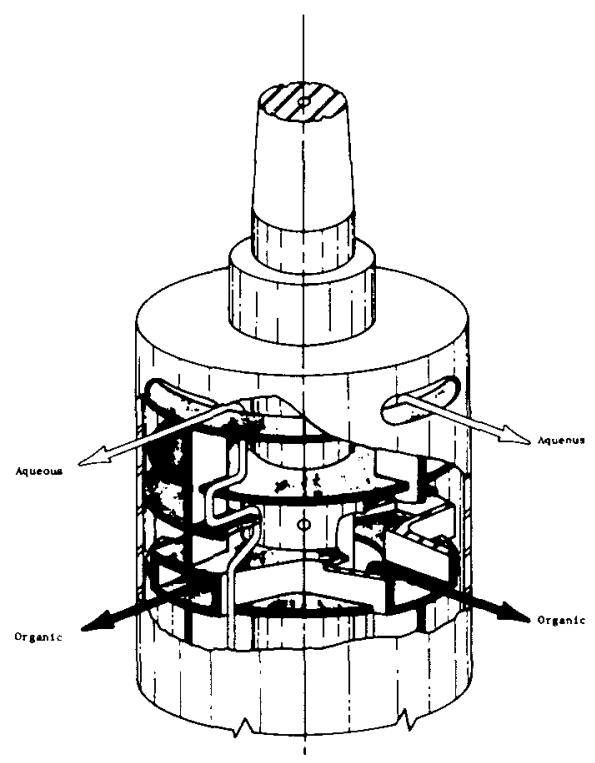

FIG. 3

Isometric View of Air-Controlled Weir

The air-controlled weir system was developed at Savannah River and is described in detail in their report. 2 The air-controlled weir permits operation of the contactor with a broader range of flow rates, flow ratios, density ratios, and rotor speeds than could be employed with simple fixeddimension weirs. Application of the air-controlled weir to the ANL contactor is described in the companion report. 1

As the volume of emulsion fed to the rotor increases (at constant rotor speed), the quantity of unseparated emulsion in the rotor also increases. Ultimately, the emulsion band becomes so wide that it is not possible, by further shifting of its position, to prevent some emulsion from discharging with both separated phases. When contamination of each effluent stream by the other reaches $1 \%$, the contactor is arbitrarily said to be operating at its maximum separating capacity.

To operate the contactor in the annular mixing mode, three basic modifications of the contactor are made: (1) the mixing chamber, paddle, radial baffle plate, and nozzle plate are removed; (2) a bottom section is attached that is fitted with a modified radial baffle plate; and (3) the organic and aqueous inlet lines are attached to the side inlets on the stator (or casing). The modified design is shown in Fig. 4.

Mixing occurs as the solutions flow downward through the annulus between the spinning rotor and the casing. The mixture then flows past the bottom baffle plate into the orifice in the bottom of the rotor. Thereafter, flow and phase separation occur as described above for operation with SR-type mixing. 


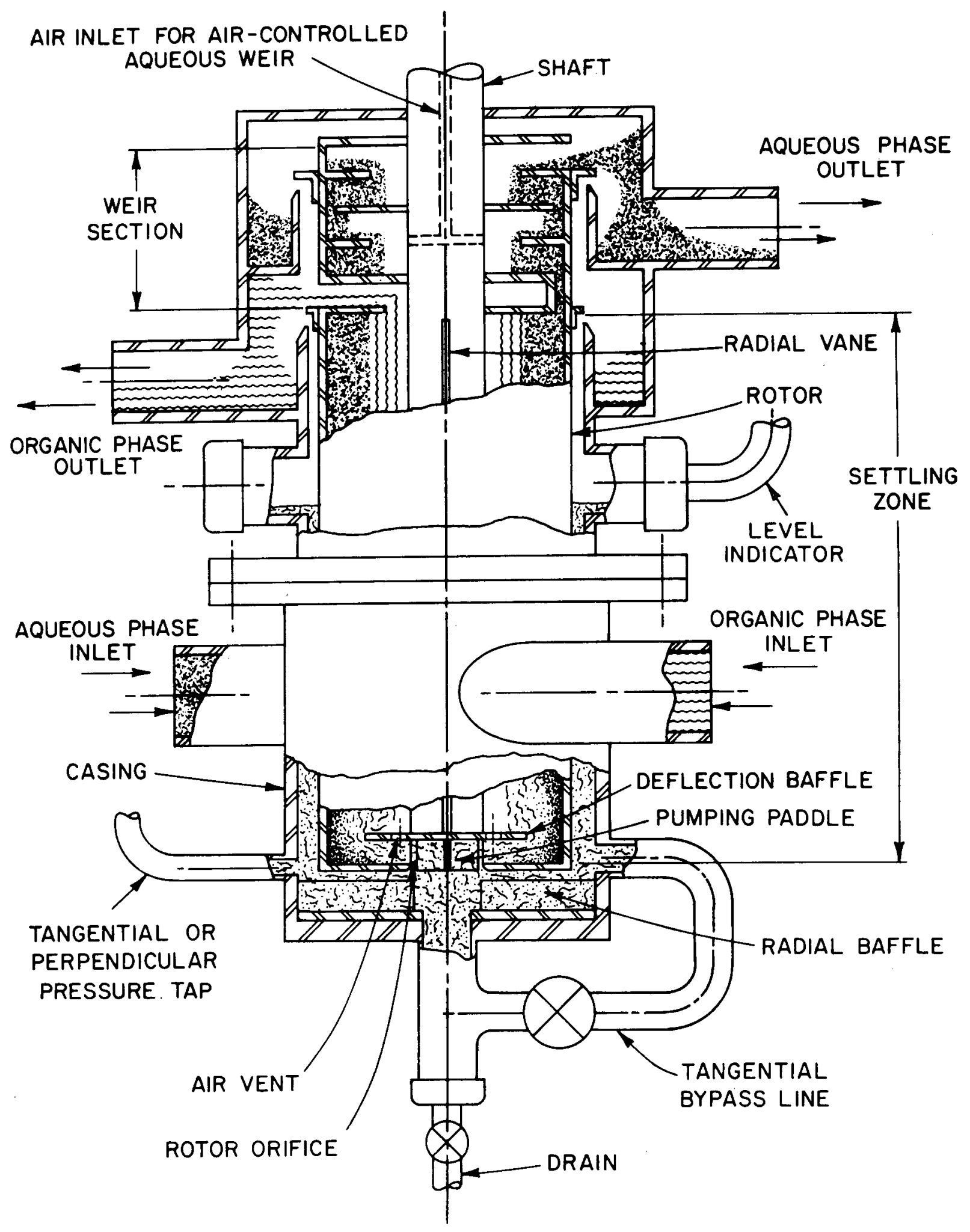

FIG. 4. Schematic Drawing of Annular Centrifugal Contactor 


\section{TEST FACILITY}

The same test facility was used for the annular mode of contactor operation as was used for the SR design. A detailed description is provided in Reference 1.

\section{PERFORMANCE TESTS}

\section{A. Preliminary Tests with a Plastic Contactor}

As part of the evaluation of the annular mixing mode, preliminary tests were made with water in several plastic contactors, each with a plastic rotor operating in a plastic casing. In these tests, throughput capacity of a 4-in. $-O D$ rotor operating at various speeds with a variety of orifice sizes, annular gaps, and depths of water in the annulus was measured. With a 1/4-in.-wide annulus filled to a $93 / 4-i n$. depth, rotor throughput rates were $9.9,9.6$, and $6.6 \mathrm{gpm}$ with rotor orifices of $11 / 2-$, 1-, and 3/4-in.-dia, respectively. These throughput rates were essentially constant over a rotor speed range from $\sim 1000$ to $\sim 1650 \mathrm{rpm}$. The level of water in the annulus rose with throughput.

Increasing the annular gap to $1 / 2$ in. by substituting a 5-in.-ID casing resulted in a throughput of $11.7 \mathrm{gpm}$ with a 1 1/8-in.-dia orifice in the rotor. Throughput was constant over the range of rotor speeds tested with this setup, suggesting that throughput was being limited by flow through the orffice, rather than by the pumping capacity of the rotor (which would increase as the rotor speed increased). It was also observed that the throughput was dependent on the height of liquid in the annulus; the higher the level in the annulus, the greater the head available to force liquid through the orifice.

On the basis of these tests, it was decided that the rotor orifice for the stainless steel unit should have a $13 / 16-i n$. dia and that the bottom edge (upstream edge) of the orifice should be rounded off to reduce pressure drop through it.

To obtain an indication of the intensity of mixing that could be developed in the annular space, mixing power tests were performed on a plastic unit. A dynamometer test stand was used in which the torque delivered by the drive motor was balanced by an applied tangential weight. 3 Power input was calculated from the measured speed and torque. In these tests, the rotor orifice was plugged to make the system nonflowing so that no power was consumed in pumping fluid through the rotor. Since the level of liquid in the annulus differs at different flow rates, power input was measured at two levels of water in the annulus.

With the $41 / 2-i n .-I D$ casing installed, tests were made over a range of rotor speeds with $29-i n$. water depth in the annulus. Power input ranged from $0.01 \mathrm{hp}$ at $910 \mathrm{rpm}$ to $0.07 \mathrm{hp}$ at $1870 \mathrm{rpm}$. In other tests with a water level of 25 in. in the annulus, the power input was about $70 \%$ of these values over the same range of rotor speeds. A test was performed with a 5-in. depth of a 50-50 mixture of water and refined kerosene in the annulus 
to measure the power consumed in mixing an emulsion. Power input values were about $50 \%$ higher than for water alone. In these tests, the increase in power input with speed was somewhat less than a third-power rise. This departure was attributed to vortexing of liquid in the annulus, which reduced the area of contact between the rotor and the liquid at high speeds.

In tests with the 5-in.-ID casing installed, essentially the same power input values were found as with the $41 / 2-i n$.-ID casing. At a given flow rate, residence time in the annulus with the larger casing would be about twice the residence time with the smaller. Therefore, the intensity of mixing a discrete volume of liquid in the larger annulus would be lower than in the smaller annulus, and the mixing time would be longer. The lower mixing intensity might decrease the degree of emulsification of a two-phase system and thereby facilitate subsequent separation.

An indication of the effectiveness of mixing in the annular plastic contactor was found by comparing our power input measurements with Treybal's 4 correlation. Treybal related the mixing power input to throughput in a contacting vessel and derived a relationship for predicting the effectiveness of contacting for achieving efficient mass transfer. The formula predicts that contacting is good when

$$
P / Q \simeq 200
$$

where $P=$ power input, $f t-1 b / s e c$

$Q=$ flow rate, $\mathrm{ft}^{3} / \mathrm{sec}$

For a total throughput of mixed phases of $10 \mathrm{gpm}\left(0.022 \mathrm{ft}^{3} / \mathrm{sec}\right)$ and

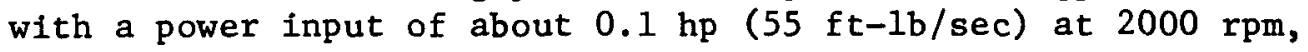

$$
\mathrm{P} / \mathrm{Q}=\frac{55}{0.022}=2500 \text {. }
$$

This high value suggested that intensive phase contacting is achieved within the annular space of the annular contactor and that effective mass transfer should occur when operating with a two-phase system.

\section{B. Separating Capacity for Stainless Steel Contactor}

Preliminary separating capacity tests were made after the experimental SR type of contactor was modified for testing in the annular mode. The tests were made with Purex-type solutions--0.5M $\mathrm{HNO}_{3}$ as the aqueous phase and $30 \%$ TBP in $n$-dodecane as the organic phase. The preliminary tests showed that excellent phase mixing and separation could be achieved. However, due to flow restriction through the narrow (0.275-in.) annular gap, the maximum feasible throughput was about $5 \mathrm{gpm}$ at rotor speeds of 1500 to $3000 \mathrm{rpm}$. When the input exceeded $5 \mathrm{gpm}$, the level of the emulsion in the annulus rose until the emulsion overflowed the inner wall of the organic phase collector ring (just inside the organic phase outlet, Fig. 4), contaminating the effluent organic phase. 
In order to increase the capacity of the contactor, the bottom section of the casing was removed, and a new bottom section was attached at a flange, as shown in Fig. 5. The flanged connection allowed experimentation to be done alternately with the annular and SR-type bottom sections. The diameter of the new, lower casing section was larger than in the original section, providing an annular gap of $0.55 \mathrm{in.} \mathrm{Also,} \mathrm{the} \mathrm{size} \mathrm{of} \mathrm{the} \mathrm{inlet} \mathrm{lines}$ was increased and they were attached closer to the bottom of the casing. The inlet lines were connected tangentially to the casing to take advantage of any drag effects by the rotating fluid, which would reduce entrance pressure head losses. The base of the lower casing section was tapped to permit baffle plates of different designs to be attached. Fig. 6 shows a plate with straight baffles and Fig. 7 shows a plate with curved baffles.

A limited number of separating capacity tests were made using $0.5 \mathrm{M}$ $\mathrm{HNO}_{3}$ as the aqueous phase and $30 \%$ TBP in n-dodecane as the organic phase. Rotor speeds ranged from 2000 to $3500 \mathrm{rpm}$ and aqueous-to-organic (A/O) ratios from 0.25 to 4 . (The separating capacity tests at $A / 0=4$ were made with uranium in the feed solution. The presence of uranium is assumed to have little effect on actual separating capacity.)

Separating capacities increased as a result of the higher flow rates permitted by the larger annular gap, and at all operating conditions capacities were not limited by flow restriction in the annulus, as had been true with the earlier design. Results are shown in Fig. 8. In general, capacities were about the same as those found when the unit was operated in the SR mixing mode, except that minimum capacities at all speeds were found at $\mathrm{A} / \mathrm{O}=2$ rather than at $\mathrm{A} / \mathrm{O}=1$. In this respect, the performance of the ANL annular unit conformed closely to that of the large SR contactor. 2 The difference in performance of the ANL contactor in the two mixing modes is attributed to differences in the nature of the emulsion formed by the two types of mixing.

\section{Hydraulic Performance}

During the separating capacity tests, pressure taps in the contactor casing were used to measure static and dynamic pressures at various points. Two taps were located near the bottom of the casing just above the radial vanes; one was installed perpendicularly to the circumference to measure static pressure, and the other tangentially to measure the kinetic energy of the fluid spinning in the annulus when converted to pressure head. The third tap was located in the bottom plate just below the rotor orifice to measure the net pressure of the fluid entering the orifice. These taps were connected to polyethylene standpipes to permit observation of the liquid head. Standpipes were also connected to the original side inlets (at the higher elevation) to allow observation of the level of fluid in the annulus.

Observation of the standpipes during the various runs showed that (as expected) the static head (pressure) was slightly greater than the height of fluid in the annulus, and the level of fluid representing the tangential pressure was about twice as high. The pressure head developed below the rotor orifice was about equal to the height of fluid in the annulus. Somewhat higher pressures had been anticipated at the rotor orifice since the 


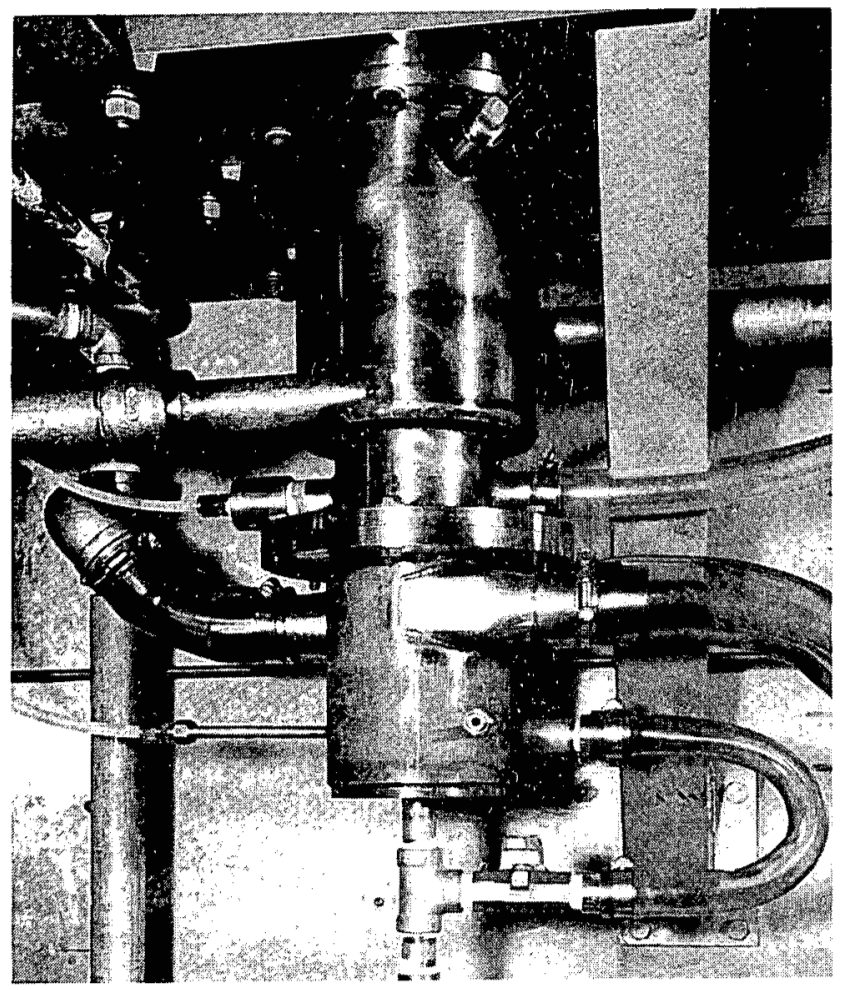

\section{FIG. 5}

Experimental Annular-Mixer Centrifugal Contactor with Large Bottom Section (ANL Neg. No. 308-2848)
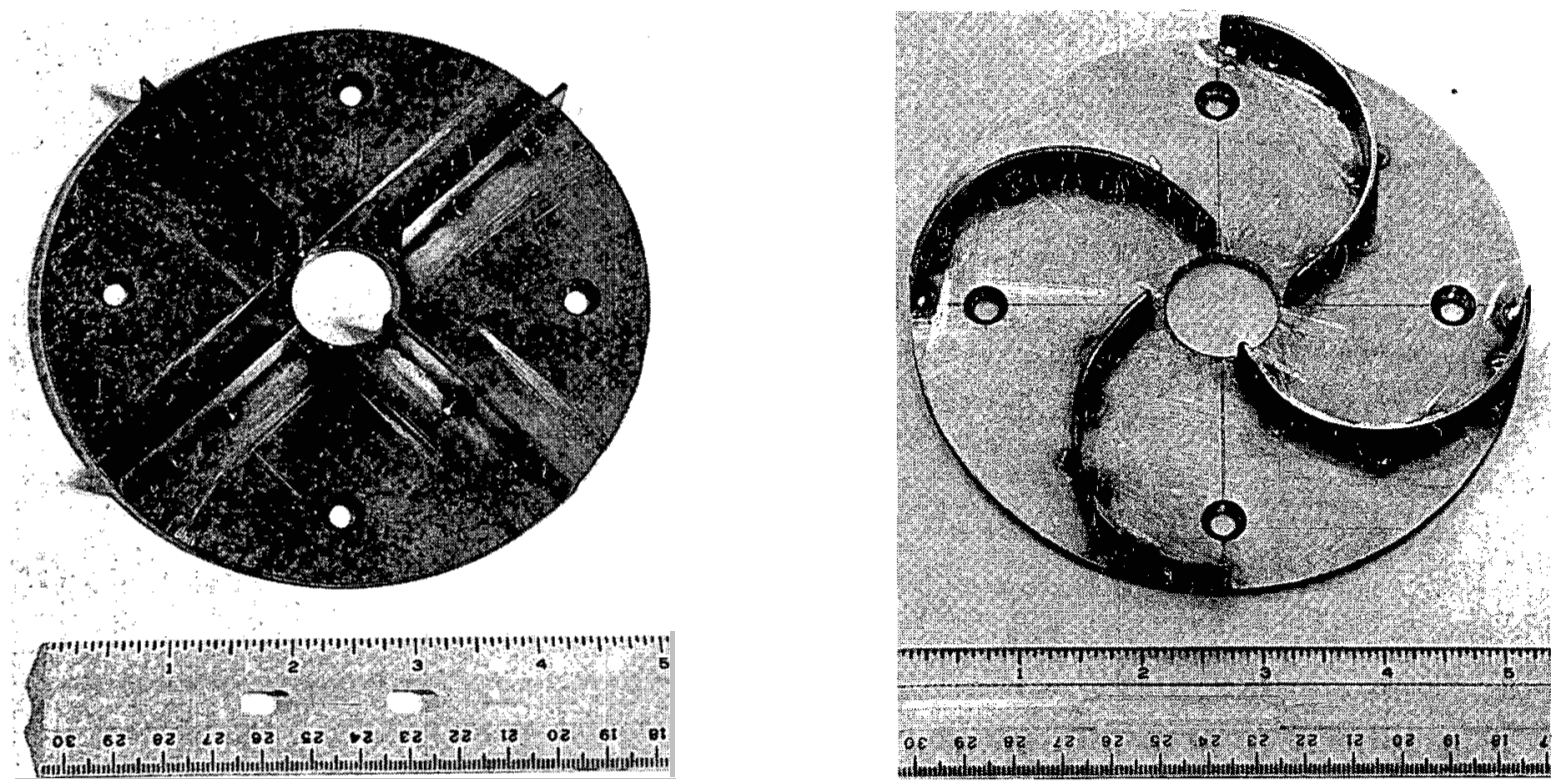

FIG. 6. Baffle Plate--Straight Baffles (ANL Neg. No. 308-2846)

FIG. 7. Baffle Plate--Curved Baffles (ANL Neg. No. 308-2962) 


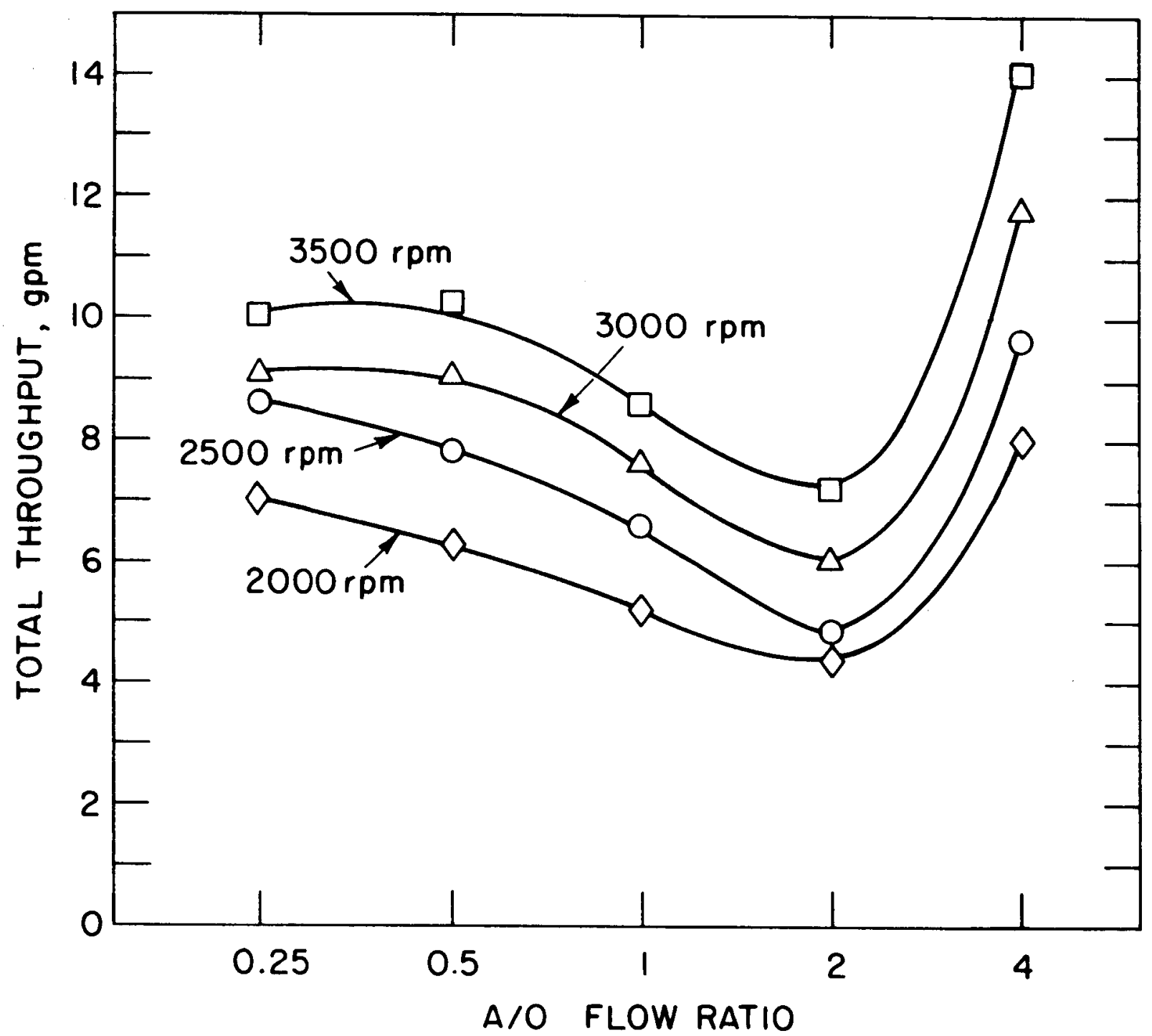

FIG. 8. Separating Capacity of Centrifugal Contactor with 4-in.-dia Rotor--Annular Mixing Mode: Aqueous Phase, $0.5 \mathrm{MNO}_{3}$; Organic Phase, $30 \% \mathrm{TBP}$ in $\mathrm{n}$-dodecane; $1 \%$ Entrainment 
radial vanes at the bottom were expected to convert some of the kinetic energy of the rotating liquid in the annulus into pressure head to drive the fluid emulsion through the rotor orifice. The lower pressure head found may in part have been due to skin friction between the bottom surface of the rotor and the emulsion, causing the part of the emulsion above the baffles to rotate and develop a centrifugal force so that the fluid was thrown away from the orifice. In addition, vigorous agitation in the annulus caused air to be whipped into the emulsion, resulting in a lower fluid density. The net effect of these factors was that the fluid level in the annulus was higher than expected. In addition, the level of fluid in the annulus rose not only when throughput increased but also when the rotor speed increased. Consequences of the rise of fluid in the annulus with increased flow rate were an increase in mixed volume and an increase in mixing effectiveness, rather than a decrease, as occurs in the SR design with its fixed-volume mixing chamber. When both the flow rate and the rotor speed are increased, there may be a tendency to overmix, and phase separation in the rotor may then become more difficult.

The curved baffles (Fig. 7) were somewhat more effective than the straight baffles (Fig. 6) in converting kinetic energy into pressure. Use of the curved baffles resulted in slightly lower fluid levels in the annulus.

Also tested was the effect of a small paddle attached to the rotor shaft just above the orifice. This paddle, by tending to pump fluid from the zone immediately above the orifice toward the periphery, enhanced the flow of fluid into the rotor. This change resulted in further reduction in the level of fluid in the annulus. (A rotor designed specifically for an annular centrifugal contactor would have the rotor vanes extended to the orifice, avoiding the need for this paddle.)

In order to investigate more fully the effects of different levels of liquid in the annulus, a bypass line was installed as shown in Figs. 4 and 5. This line permitted some of the fluid to flow from the annulus directly into the rotor orifice. Its use has a dual effect, to reduce the level of fluid in the annulus and to reduce the overall mixing intensity. The effect of the bypass line is discussed further below.

\section{Effect of Solids on Contactor Operation}

The usual practice in plants for processing fuel by solvent extraction methods is to clarify by centrifuging the solution prepared in the acid dissolver. This removes the larger, undissolved particulate solids. However, two kinds of solids may remain in the centrifuged solution fed to a contactor--(1) fine, heavy particles and (2) insoluble reaction products generally called "interface crud." Accumulation of such solids in the rotor of a centrifugal contactor might make it inoperable.

At Savannah River, ${ }^{2}$ the behavior of solids in the feed to the centrifugal contactors was evaluated by using feed solutions containing various quantities of manganese dioxide. Freshly made $\mathrm{MnO}_{2}$ tends to be quite flocculent and to settle very slowly in an aqueous medium. Because the amount of $\mathrm{MnO}_{2}$ that will collect in a rotor is sensitive to its physical form, widely varying amounts can accumulate in a centrifugal contactor. 
Thus, in a test of the multistage 10-in.-dia SR contactor using feed containing $5000 \mathrm{ppm}$ of $\mathrm{MnO}_{2}$, approximately $2 \mathrm{~kg}$ had accumulated in each unit when steady-state conditions were reached, whereas only $25 \mathrm{~g}$ of $\mathrm{MnO}_{2}$ had collected in similar single-stage tests. However, the presence of even the large bulk of solids in the rotor in multistage tests did not interfere with the hydraulic performance of the contactors.

Two tests were made in the experimental ANL annular contactor with $\mathrm{MnO}_{2}$ in the aqueous feed. The $\mathrm{MnO}_{2}$ was prepared by adding $\mathrm{NH}_{4} \mathrm{OH}$ to a solution of $\mathrm{KMnO}_{4}$. Two concentrations of $\mathrm{MnO}_{2}$ were used, $1400 \mathrm{ppm}$ and $1600 \mathrm{ppm}$, and both tests were made at an A/O ratio of 1 using $0.5 \mathrm{M} \mathrm{HNO}_{3}+$ $\mathrm{MnO}_{2}$ as the aqueous feed and $30 \% \mathrm{TBP}$ in $\mathrm{n}$-dodecane as the organic feed. One run (123A) was made at 2000-rpm rotor speed and 4-gpm total throughput and the other run (123B) at $3500 \mathrm{rpm}$ and 7-gpm throughput. (During these tests, the filter was absent from the aqueous supply line so that $\mathrm{MnO}_{2}$ would not be separated from the circulated aqueous phase.)

It was observed that $\mathrm{MnO}_{2}$ appeared in the aqueous effluent stream immediately after startup, indicating that at no time was all suspended material separated from the aqueous phase. The relative concentration of $\mathrm{MnO}_{2}$ in the aqueous effluent stream was determined periodically by centrifuging 115-ml samples and observing the level of settled solids. After about $30 \mathrm{~min}$ of operation, the quantity of $\mathrm{MnO}_{2}$ in the effluent stream became uniform and appeared to be equal to the quantity in a feed-solution sample. After about $1 \mathrm{hr}$ of operation, 1-liter samples of the feed solution and the aqueous phase effluent stream were taken and filtered. The solids were subsequently dried and weighed, establishing that an equilibrium condition had been achieved. No $\mathrm{MnO}_{2}$ solids were observed in the organic phase effluent stream in any of the tests. Following each test, the $\mathrm{MnO}_{2}$ accumulated in the rotor was removed by flushing with water followed by flushing with oxalic acid and nitric acid solutions.

Results are tabulated in Table 1. The quantities of $\mathrm{MnO}_{2}$ found in the rotor in these runs were about half as great as had been found in similar runs with the ANL contactor operated in the SR mode with feed containing about $2500 \mathrm{ppm} \mathrm{MnO}_{2}{ }^{1}$ These results show that even with the very high solids loading in the feed, relatively little material was retained in the rotor. No operating difficulties were encountered in these runs, and it is quite reasonable to assume that the much lower concentrations of interface crud likely to be found in Purex-type process solutions would cause no difficulties.

\section{E. Determination of Extraction Efficiency}

Extraction efficiency of the centrifugal contactor was determined by the transfer of uranium between an aqueous nitric acid solution and $30 \%$ TBP in $\mathrm{n}$-dodecane. Since only a single-stage contactor was being tested, no attempt was made to duplicate Purex process operating conditions.

In the first set of tests, the transfer of uranium from the aqueous phase to the organic phase was tested. The composition of the aqueous stream was $0.41 \mathrm{M}$ uranium and $0.88 \mathrm{M}^{\mathrm{HNO}}{ }_{3}$; the organic stream contained $0.100 \mathrm{M}$ uranium and $0.046 \mathrm{M}^{\mathrm{HNO}}{ }_{3}$; the rotor was operated over the range 
TABLE 1. Summary of Contactor Runs with $\mathrm{MnO}_{2}$ Solids (Annular Mixing Mode)

\begin{tabular}{lrr}
\hline \multicolumn{1}{c}{ Run No. } & $123 \mathrm{~A}$ & $123 \mathrm{~B}$ \\
\hline $\mathrm{MnO}_{2}$ Conc, In Feed, ppm & 1600 & 1400 \\
Total Feed Rate $(\mathrm{A} / \mathrm{O}=1$ ), gpm & 4 & 7 \\
Rotor Speed, rpm & 2000 & 3500 \\
Running Time, min & 75 & 45 \\
Aqueous Throughput, gal & 150 & 155 \\
Retained $\mathrm{Mno}_{2}, \mathrm{~g}$ & 53 & 50 \\
\hline
\end{tabular}

2000 to $3500 \mathrm{rpm}$. Tests were conducted in sets of five. Each test in a set followed immediately after the preceding test.

Stock solutions were prepared in the supply tanks of the test facility. Approximately $20 \mathrm{gal}$ of each phase was pumped into its overhead tank, which then served as a supply tank. During the tests, the inlet streams flowed by gravity through the rotameters to the contactor and out into collecting tanks. Flowrates were regulated by the inlet line valves. Flowrates, weir pressure, and rotor speed were adjusted as specified for a given run. Since the contactor achieves steady-state operation in well under one minute, it was possible to make a set of five runs in about five minutes. At each run condition, samples of effluent streams were taken before changing to the operating conditions for the next run. Equal-volume aliquots of effluent samples from each run were equilibrated by vigorous shaking to obtain data on uranium concentrations in the aqueous phase at equilibrium.

Stage efficiencies, $E_{A}$, were determined on the basis of aqueous compositions using the equation:

$$
E_{A}=\frac{A_{i}-A_{0}}{A_{i}-A_{e}} \times 100
$$

where $A_{i}=U$ concentration, $M$, in aqueous feed, $A_{0}=U$ concentration, $\vec{M}$, in aqueous effluent, $A_{e}^{O}=U$ concentration, $\vec{M}$, in aqueous effluent after equilibration with an equal volume of organic effluent.

All samples were analyzed using colorimetric analyses; results are accurate within about $2-3 \%$. 
Extraction efficiencies based upon organic sample compositions, $E_{0}$, were determined using the equivalent formula:

$$
E_{0}=\frac{o_{0}-0_{i}}{0_{e}-0_{i}} \times 100
$$

where $O_{0}=U$ concentration, $\underline{M}$, in organic effluent,

$0_{i}^{O}=U$ concentration, $\bar{M}$, in organic feed,

$0_{e}=U$ concentration, $\bar{M}$, in organic effluent after equilibration with an equal volume of aqueous effluent.

Values of $E_{O}$ and $E_{A}$ and average $E$ values are summarized in Table 2 .

TABLE 2. Stage Efficiencies in Uranium Extraction

(Annular Mixing Mode)

Aqueous Phase: $0.410 \mathrm{M} \mathrm{U}, 0.88 \mathrm{M} \mathrm{HNO} 3$

Organic Phase: $0.100 \overline{\mathrm{M}} \mathrm{U}, 0.04 \overline{\mathrm{M}} \mathrm{HNO}_{3}$ in $30 \% \mathrm{TBP}$ in n-dodecane Aqueous-Organic $(\mathrm{A} / 0): 1$

\begin{tabular}{lccccc}
\hline Run & Rotor Speed, rpm & Total Flowrate, gPm & $\mathrm{E}_{\mathrm{A}}, \%$ & $\mathrm{E}_{\mathrm{o}}, \%$ & $\mathrm{E}_{\text {Ave }} \%$ \\
\hline UXA-1a & 2000 & 4 & 113 & 100 & 107 \\
UXA-1b & 2500 & 4 & 105 & 98 & 101 \\
UXA-1c & 3000 & 4 & 105 & 97 & 101 \\
UXA-1d & 3000 & 7 & 98 & 94 & 96 \\
UXA-1e & 3500 & 7 & 97 & 97 & 97 \\
\hline
\end{tabular}

Examination of the data in the table shows that stage efficiency in every run was essentially $100 \%$. It is clear that excellent phase mixing was achieved, even under conditions of relatively low rotor speed. Since residence times in the mixing chamber were about 2 or $3 \mathrm{sec}$, these tests demonstrate the very rapid attainment of equilibrium in uranium extraction. Material balances based upon the assumption of equal solution flow rates ranged between 97 and 104\% in runs UXA-la through UXA-le, indicating that the A/O ratio of 1 was very closely maintained during these runs.

Two sets of runs (USA-1 and USA-2) were made to measure stage efficiency of the centrifugal contactor in the transfer of uranium from an organic phase into an aqueous phase (stripping). In all runs, the input organic phase was $30 \% \mathrm{TBP}$ in $\mathrm{n}$-dodecane diluent containing $0.304 \mathrm{M} \mathrm{U}$ and $0.42 \mathrm{M} \mathrm{HNO}_{3}$. (This material was the product stream from the uranium extraction runs reported above.) The aqueous stripping solution was $0.049 \mathrm{M} \mathrm{HNO}_{3}$. The 
A/O ratio was held at 1 for all runs; the total flow rate was $4 \mathrm{gpm}$ in the first three runs of a set and $7 \mathrm{gpm}$ in the last two runs. Rotor speeds ranged from 2000 to $3500 \mathrm{rpm}$. Run conditions were changed without shutting down the equipment so that a set of 5 runs was completed in about 5 min, as above in the extraction experiments. Aqueous and organic effluent samples were taken simultaneously for analysis of effluent compositions. Equal-volume portions of these samples were also equilibrated by vigorous shaking to obtain data on uranium concentrations in the aqueous and organic phases at equilibrium.

The first set of tests (USA-1) was made with the tangential bypass line shut (see Figs. 4 and 5) and the second set (USA-2) with the line open. In USA-1, the level of liquid in the annulus rose from $25 \mathrm{in}$. to UI in. above the casing bottom as conditions changed from $4 \mathrm{gpm}$ total flow at $2000 \mathrm{rpm}$ to $7 \mathrm{gpm}$ at $3500 \mathrm{rpm}$. In USA-2, with the bypass open, the level rose from $3.5 \mathrm{in}$. to $7.5 \mathrm{in.}$ for the same flow rates and rotor speeds. In comparison, the top of the inlet lines is $6 \mathrm{in}$. above the casing bottom. The effect of the open bypass was essentially to reduce the extent of phase mixing. However, stage efficiencies were uniformly high in both sets of runs, indicating that the reduced mixing in USA-2 had no significant effect.

Stage efficiencies for stripping runs USA-1 and USA-2 are shown in Tables 3 and 4 , respectively. Efficiencies were all essentially $100 \%$, within the accuracy of sample analyses. At first glance, these high stage efficiencies seem a bit unusual. Experience at Savannah River ${ }^{2}$ and Karlsruhe ${ }^{5}$ with the SR type of design have generally shown stripping efficiencies of $295 \%$ although extraction efficiencies were found to be very close to $100 \%$. This difference was attributed to stripping kinetics being somewhat slower than extraction kinetics at room temperature and to residence times being too short for $100 \%$ equilibrium in the stripping runs. In the ANL annular contactor, residence times are estimated to be almost twice as long in the annular mixing mode as in the SR mixing mode when the total throughput is $4 \mathrm{gpm}$ and more than twice as long when the throughput is $7 \mathrm{gpm}$. Since the volume of the ANL SR-mode mixing chamber is $0.13 \mathrm{gal}$, the residence time is $\sim 2 \mathrm{sec}$ at $4 \mathrm{gpm}$ throughput and $\sim 1.1 \mathrm{sec}$ at $7 \mathrm{gpm}$. The volume of the mixing chamber in the annular mode is less precisely determined, since the height of liquid in the annulus depends on the flowrate, as well as the rotor speed. If the height in the annulus is estimated to be $\sim 4$ in. at a flow of $4 \mathrm{gpm}$, the estimated residence time is $23.2 \mathrm{sec}$. The effective height of liquid is 6 in. at $7 \mathrm{gpm}$ and the residence time is $22.5 \mathrm{sec}$. (The "effective" height of the annulus is limited to $\sim 6$ in., which is the elevation of the top of the inlet lines. Although the level of liquid in the annulus can rise above this point, the liquid above the top of the inlet lines is somewhat isolated and the volume below the top of the inlets represents more nearly the actual mixing zone volume).

Based on the assumption of equal aqueous and organic volumetric flowrates, material balances in USA-1 ranged from 97 to $100.3 \%$, except for USA-Ia. This shows that the $A / O$ ratio of 1 was maintained closely in all but one case. In USA-2, material balances ranged from 98 to $101.5 \%$. 
TABLE 3. Stage Efficiencies in Uranium Stripping (bypass line closed, annular mixing mode)

Aqueous Phase: $0.049 \mathrm{M} \mathrm{HNO}_{3}$ Organic Phase: $0.304 \overline{\mathrm{M}} \mathrm{U}$ and $0.42 \mathrm{M}^{\mathrm{HNO}} \mathrm{H}_{3}$ in $30 \% \mathrm{TBP}$ in n-dodecane
Aqueous-to-Organic ( $\mathrm{A} / \mathrm{O})$ Ratio: $\frac{1}{1}$

\begin{tabular}{lcccccc}
\hline Run & Rotor Speed, rpm & Total Flowrate, gpm & $\mathrm{E}_{\mathrm{A}}, \%^{\mathrm{a}}$ & $\mathrm{E}_{\mathrm{o}, \%^{\mathrm{b}}}$ & $\mathrm{E}_{\text {ave }}, \%^{\mathrm{c}}$ \\
\hline USA-1a & 2000 & 4 & 104 & 100 & 102 \\
USA-1b & 2500 & 4 & 96 & 103 & 99 \\
USA-1c & 3000 & 4 & 113 & 105 & 109 \\
USA-1d & 3000 & 7 & 114 & 100 & 107 \\
USA-1e & 3500 & 7 & 102 & 106 & 104 \\
\hline
\end{tabular}

a Stage efficiency based on aqueous samples.

Stage efficiency based on organic samples.

${ }^{c}$ Average of $\mathrm{E}_{\mathrm{A}}$ and $\mathrm{E}_{\mathrm{O}}$.

TABLE 4. Stage Efficiencies in Uranium Stripping

(bypass line open, annular mixing mode)

Aqueous Phase: $0.049 \mathrm{M} \mathrm{HNO}_{3}$

Organic Phase: $0.304 \overline{\mathrm{M}} \mathrm{U}$ and $0.42 \mathrm{M} \mathrm{HNO}_{3}$ in $30 \%$ TBP in n-dodecane Agueous-to-Organic (A/O) Ratio: $\overline{1}$

\begin{tabular}{ccccccc}
\hline Run & Rotor Speed, rpm & Total & Flowrate, gpm & $E_{A}, \%^{a}$ & $E_{0}, \%^{b}$ & $E_{a v e}, \%^{c}$ \\
\hline USA-2a & 2000 & 4 & 100 & 94 & 96 \\
USA-2b & 2500 & 4 & 105 & 103 & 104 \\
USA-2c & 3000 & 4 & 103 & 101 & 102 \\
USA-2d & 3000 & 7 & 104 & 106 & 105 \\
USA-2e & 3500 & 7 & 102 & 107 & 104 \\
\hline
\end{tabular}

${ }_{b}$ Stage efficlency based on aqueous sample analyses.

Stage efficiency based on organic sample analyses.

Average of $E_{A}$ and $E_{0}$. 


\section{v. DISCUSSION AND CONCLUSIONS}

The operating tests of the annular centrifugal contactor have demonstrated that it is a highly effective unit with respect to mechanical and extraction performance. The unique design represents a significant improvement in the construction of centrifugal contactors. The elimination of the separate mixing chamber should eliminate any of the problems of flow surging noted in Reference 1 . Because of the relatively short time devoted to the study of this unit, its operating potential was not fully evaluated, and its design was not optimized. The following comments represent the more important observations and conclusions drawn from the work.

Experience to date has been inadequate to determine the optimum width for the annular gap. The original gap of $0.275 \mathrm{in}$. appeared to be too small for flows above $25 \mathrm{gpm}$; the present gap of $0.55 \mathrm{in}$. can handle flows up to the separating capacity of the rotor ( $15+\mathrm{gpm}$ ). When the gap width was changed, the elevation of the inlet lines was also changed from $\sim 9$ in. above the casing bottom in the original design to $\sim 5 \mathrm{in}$. above the bottom. Thus, the original flow path was longer as well as narrower. Precise determination of "optimum" gap is unimportant unless the objective is to design a rotor having the maximum diameter permitted by criticality considerations. Conservative design suggests the use of a gap somewhat greater than the bare minimum needed for adequate flow capacity.

As noted previously, use of the bypass line permits direct injection of some of the liquid from the annulus into the rotor before it has been subjected to the full mixing experience in the annulus. In addition, the liquid carried through the bypass retains some of its kinetic energy, which is then converted into pressure for injection into the rotor orifice. As a result, less hydraulic head is required in the annulus for supplying this pressure, and the level of liquid in the annulus is lower than when the bypass is closed. This effect can be significant in preventing backup of emulsion from the annulus into the organic-phase collecting ring at high flowrates or high rotor speeds. Although the flexibility provided by the bypass line is useful in an experimental model, a similar effect can be readily obtained in a production-model contactor by further lowering the elevation of the inlet lines.

Tangential inlet lines were used in the experimental model so that the drag of the fluid in the annulus would reduce the pressure drop across the inlet. Our limited experience suggests that this potential benefit does not justify the higher cost of this type of construction in comparison to perpendicular junctions of the inlet lines and casing. The tangential type of connection may have an application in a bank of contactors if the presence of air in effluent streams from adjacent contactors results in excessive flow resistance in the inlet lines.

Although no detailed design evaluation has been made, it is apparent that the annular design is much more readily adaptable to remote maintenance than is the Savannah River design. In a production plant annular unit, it is assumed that the rotor will be driven by direct coupling to the drive motor as in the Savannah River production units. In the SR design, the presence of the mixing paddle in the mixing chamber prevents removal of the rotor assembly. A complex spindle bearing and rotary air seal are 
required to permit remote removal of the drive motor. In the annular design, a much simpler rotary seal can be used (similar to the one used in the ANL experimental unit), and the motor, spindle, and rotor assembly can be removed directly as an integral unit. This would permit easy replacement of the only movable parts of a bank of contactors without disturbing the casing assemblies or interstage piping. The annular design retains all of the desirable features of the SR design--small holdup, short residence time (and thus reduced solvent damage as a result of irradiation), rapid attainment of steady-state operating conditions, and rapid flushout at the end of a processing campaign.

Additional advantages of the annular design are derived from the fact that the center shaft and overhung paddle are eliminated. As a result, the rotor has a lighter weight and shorter overall length than does a rotor of the SR design and equivalent size. Consequently, the critical speed would be higher and it should be possible to produce a rotor to operate at a desired speed with less precise dynamic balancing (alternatively, a longer rotor or a higher-speed rotor could be employed). Fabrication costs for an annular contactor should be substantially less than the cost of an SR paddle-mixer contactor.

The advantages of the annular design also apply to centrifugal contactors smaller than the ANL unit. A miniature centrifugal contactor was used at Savannah River for solvent extraction process studies. This multistage unit had a separately driven mixing chamber for each 1-in.-dia separating unit. If the annular mixing chamber design had been used, separate mixing chambers could have been eliminated and phase mixing could take place in an annulus around the separating rotor.

Some features of the annular centrifugal contactor were not fully explored. These features, which are uniquely characteristics of shortresidence-time contactors, were discussed in the companion report. 1 It was pointed out that the use of short-residence-time contactors opens the possibility of employing "non-quilibrium" extraction, as reported by the Russians.7 In this technique, when a number of species are present, it might be possible to effect a separation on the basis of significant differences in reaction kinetics, as well as differences in distribution coefficients. By proper selection of the volume of the mixing zone, it would be possible to select residence times that are optimum for a given separation. Another option would be to use contactors with different sizes of mixing zones in the same bank of contactors. For example, in a Purex process, the contactors in the extraction section could have smaller mixing zones to deter extraction of fission products; the contactors in the scrub section could have larger mixing zones to enhance removal of fission products from the organic product phase. 


\section{ACKNOWLEDGMENTS}

The authors wish to acknowledge the contributions of N. Quattropani for assistance in construction and operation of test equipment and the performance of capacity and efficiency tests; D. S. Webster and A. A. Jonke for overall support and guidance of the program; H. 0 . Smith for criticalspeed calculations of the rotor and general supervision of overall design drawings; W. F. Olsen for development of the rotor speed-indicating device; A. E. Lissy for radiological monitoring during extraction runs; and E. Kucera, Z. Tomczuk, and F. Williams for analysis of samples.

\section{REFERENCES}

1. G. J. Bernstein, D. E. Grosvenor, J. F. Lenc, and N. M. Levitz, Development and Performance of a High-Speed Long-Rotor Centrifugal Contactor for Application to Reprocessing LMFBR Fuels, USAEC report ANL-7968 (January 1973).

2. A. A. Kishbaugh, Performance of a Multistage Centrifugal Contactor, USAEC report DP-841 (October 1963).

3. Chemical Engineering Division Summary Report, July, August, September 1962, USAEC report ANL-6596, PP. 84-87 (1962).

4. R. E. Treybal, Liquid Extraction, McGraw-Hill, 2nd ed., 1963, p. 427.

5. W. Knoch and B. Roth, Fast Contactors in the WAK, IAEA Panel on Reprocessing of Highly Irradiated Fuels, Vienna, May 1969, KFK-989 (June 1969).

6. A. S. Jennings, A Miniature Centrifugal Contactor, USAEC report DP-680 (March 1962).

7. M. F. Pushlenkov, et al., Study of the Extraction Kinetics of Uranium, Plutonium, Ruthenium, and Zirconium with Tributyl Phosphate with Liquid Mixing in a Centrifugal Field, ORNL-tr-2612 (1971). 